\title{
Desenvolvimento de Sistema Produto+Serviço para transporte de pessoas idosas
}

\author{
Product Service System development for transportation of elderly people
}

ALVES, Milena Carneiro; Mestranda; Universidade Federal do Paraná

mcarneiroalves@gmail.com

MÜLLER, Aline Garcia; Mestranda; Universidade Federal do Paraná

Eilan.muller@gmail.com

SANTOS, Aguinaldo dos; PhD; Universidade Federal do Paraná

asantos@ufpr.br

\section{Resumo}

Este artigo é um relato de projeto desenvolvido durante a disciplina eletiva de Design de Serviços do PPGDesign da UFPR. O seu objetivo é evidenciar a importância da participação do usuário nas etapas de um projeto PSS; além de demonstrar como as ferramentas de coleta e análise de dados podem ser utilizadas para o desenvolvimento de um modelo de PSS. Como método utilizou-se a revisão de literatura e pesquisa de campo. A primeira foi utilizada para contextualizar a importância do desenvolvimento de serviços para idosos e os conceitos do PSS. A pesquisa de campo foi aplicada com idosos residentes do lar e creche Nurse Aid localizado em Curitiba-PR. A imersão no contexto dos idosos auxiliou todas as etapas da pesquisa, desde a identificação do problema até a validação dos resultados. Dessa forma chamou a atenção para as necessidades dos idosos e também para mostrar o potencial do PSS neste contexto.

Palavras Chave: Sistema Produto + Serviço, mobilidade, idosos, População Marginalizada

\begin{abstract}
This paper is about a project developed during an elective class of Service Design of PPGDesign of UFPR. Its purpose is to highlight the importance of user participation in the stages of a PSS project; as well as to demonstrate that data collection and analysis tools can be used for the development of a PSS project. The literature review and field research were used as a method of this research. The first one was used to contextualize the importance of services for the elderly. The field survey was applied at a elderly residence called NurseAid located in Curitiba-PR. The immersion in the context of the elderly helped all stages of the research, from the identification of the problem to the validation of the results. In this way this paper drew attention to the needs of the elderly and also about the potential of the PSS in this context.
\end{abstract}

Keywords: Product Service System, Mobility, Elderly people, Marginalized Population 


\section{Introdução}

O Sistema Produto+Serviço (PSS) é uma estratégia que permite a solução de problemas de diversos níveis sem a necessidade da produção de novos artefatos físicos. (VEZZOLI et.al, 2014). O foco do processo de PSS é envolver o usuário diretamente nas etapas da pesquisa, como foi feito no estudo para o desenvolvimento de PSS voltado ao público idoso, relatado no presente artigo.

Durante a disciplina eletiva de Design de Serviços do PPGDesign da Universidade Federal do Paraná foi proposto aos estudantes o desenvolvimento de um modelo de PSS voltado a fatores que envolvessem a mobilidade do público idoso. Neste artigo são relatados os aspectos práticos e teóricos que fundamentaram a pesquisa, desde a caracterização do problema até a etapa de prototipagem do serviço.

O estudo foi realizado em duas etapas: revisão bibliográfica e pesquisa de campo. A revisão bibliográfica contribuiu para verificar os dados quantitativos que embasaram a importância da pesquisa. A pesquisa de campo foi realizada com os idosos residentes no lar e creche para idoso NurseAid, localizado em Curitiba- Paraná por meio de conversas informais, entrevistas narrativas e ferramentas de análise para obter-se informações a respeito dos problemas relacionados a mobilidade que os idosos enfrentam.

Assim, foi verificada a possibilidade de resolver as questões identificadas na pesquisa de campo por meio do desenvolvimento de um modelo de PSS pelo qual seja possível diminuir a produção de artefatos tangíveis, contribuindo com a desmaterialização do consumo e ao mesmo tempo melhorando a qualidade de vida dos idosos.

O foco do modelo de PSS aqui relatado foi a solução de problemas relacionados ao transporte de idosos de modo que seja possível manter ou devolver-lhes autonomia nesse processo. Inicialmente apresenta-se um breve estudo teórico realizado por meio de revisão bibliográfica para contextualizar o assunto; em seguida, apresentam-se as etapas do método utilizado com aplicação de ferramentas do design de serviços para análise, criação e prototipagem do serviço proposto.

\section{Contexto Teórico}

Este artigo relata o desenvolvimento de um serviço voltado à mobilidade de idosos que, seja por dificuldades físicas, cognitivas ou mentais decorrentes do avanço da idade, perderam a autonomia no transporte. Observa-se a necessidade de contextualizar os dois temas centrais desta pesquisa: idosos e design de serviços.

\subsection{Dados Sobre Idosos e Mobilidade}

Há um crescente aumento da população idosa no Brasil. Em 2005 os idosos eram 9,8\% da população e em 2015 esse número foi para 14, 3\% (IBGE, 2012). As pesquisas estatísticas indicam que a tendência é o aumento contínuo desse percentual. De acordo com a Organização Mundial da Saúde (OMS) em 2050 o Brasil terá 64 milhões de idosos, o que corresponde a 30\% da população nacional. Esse crescimento é um fator importante para esta pesquisa, pois indica um 
aumento na demanda por produtos e serviços voltados a esse público. Dentre as regiões do país, a região Sul (onde a pesquisa foi aplicada), é a segunda a apresentar o maior número de idosos, sendo que a população idosa cresce quatro vezes mais que a população não idosa na região (CAMARANO et al., 2008).

Com esse aumento, existe também uma demanda para atender as necessidades dessa parcela da sociedade. As instituições de longa permanência para idosos também tiveram maior destaque nos últimos anos, de acordo com pesquisa de Camarano (2008), na época em que foi realizada a pesquisa, $9 \%$ da população da região sul era idosa, sendo que $0,6 \%$ residiam em instituições de longa permanência para idosos. Junto com a idade, observa-se a perda da autonomia física e cognitiva, um fator que leva muitas famílias a buscarem instituições para hospedar seus familiares (CAMARANO et al., 2008). O desenvolvimento do serviço relatado nesta pesquisa se aprofundou nos casos de idosos que vivem em instituições, porém, o serviço desenvolvido pode ser utilizado por qualquer pessoa que precise de segurança e cuidados para realizar seu transporte.

A mobilidade é um ponto complicado e importante a se considerar, tendo em vista o crescente aumento da população idosa, o que sugere uma demanda por soluções para este contexto. Rosa (2015) verificou, por meio de entrevistas com idosos, que as principais barreiras que dificultam a sua autonomia em relação ao transporte são: condições precárias de estações de transporte coletivo, motoristas despreparados para atender os idosos, dificuldade em interpretar informações sobre rotas e horários, superlotação dos veículos e falta de gentileza de funcionários e passageiros. Os idosos que ainda dirigem relatam falta de paciência dos outros motoristas e dificuldades de encontrar vagas identificadas nos estacionamentos. Outra barreira encontrada na pesquisa foi à falta de segurança, riscos de assaltos e outros problemas que os idosos, por terem a mobilidade e agilidade reduzida, se tornam mais vulneráveis. Dessa forma, procurou-se levar em consideração fatores como o crescimento da população idosa e as dificuldades relacionadas à mobilidade para fundamentar a criação do serviço apresentado neste artigo.

\subsection{Design de Serviços e o Sistema Produto+Serviço}

Segundo Costa Junior (2012), a área Design de Serviços surgiu em 1990, e no geral, é um processo de desenvolvimento que integra vários campos de conhecimento, os quais fornecem ferramentas e técnicas. Blomkvist (2011) comenta que essa área surgiu a partir da demanda de produtos mais conscientes que auxiliassem na produção de um design mais orgânico e Vezzoli (2010) afirma que o Design de Serviços no campo da Sustentabilidade e Inovação, possibilita a implantação de princípios de equidade social, econômica e ambiental. Afirmando ainda que, o Sistema Produto+Serviço (PSS) é englobado nesta área do "design para sustentabilidade" e consegue atender às necessidades e desejos dos stakeholders de forma inovadora e estratégica.

Goedkoop et al. (1999, p.18) definiu que Sistema Produto+Serviço (PSS) é um conjunto de produtos e serviços que são comercializáveis e capazes de satisfazer as necessidades de todos os stakeholders, e esse conjunto é nomeado sistema, que pode gerar baixo impacto ambiental. Para a UNEP (2002), o PSS é uma estratégia de inovação que muda o centro do negócio de design da venda física para a venda de serviços com o objetivo de oferecer soluções sustentáveis e reorientar as práticas de produção e consumo de forma desmaterializada. Podendo criar, assim, maior valor a partir do consumo de materiais, reduzindo o impacto ambiental significativamente 
no ciclo de vida de sistemas mais tradicionais. Tukker (2003) aponta que o PSS possui 03 categorias distintas, o Sistema Produto+Serviço orientado ao Produto, o Sistema Produto+Serviço orientado ao uso e o Sistema Produto+Serviço orientado ao Resultado.

Para Ceschin e Gaziulusoy (2016), a inovação do Sistema Produto+ Serviços (PSS) é uma abordagem promissora para a sustentabilidade. Segundo os autores, o PSS são proposições de valor geradas para satisfazer os usuários por meio da entrega de serviços em vez de apenas produtos, implicando na mudança de consumo do usuário. Vários projetos de pesquisa focados em PSS para Ecoeficiência foram financiados pela União Europeia com intuído de explorar a inovação do PSS e a sua implicação para o design (CESCHIN; GAZIULUSOY, 2016).

A ecoeficiência, segundo Ceschin e Gaziulusoy (2016) é a transformação dos recursos ambientais no bem requerido. Vezzoli (2010) comenta sobre as seis orientações listadas pelo MEPSS- União Europeia (Methodology for Product Service System Development) para obter ecoeficiência: otimizar a vida do sistema, reduzir o consumo na distribuição e transporte, reduzir o uso de recursos, minimizar/valorizar resíduos, biocompatibilidade, e reduzir a toxidade.

Mas pensar que um PSS é apenas voltado para a ecoeficiência é uma interpretação muito rasa. Vezzoli (2010) afirma que o PSS não é apenas uma inovação tecnológica que foca na questão ambiental, mas também na questão social, cultural, econômica e organizacional. De acordo com a Vezzoli et al. (2015, p.2), um PSS, é um modelo de oferta que oferece uma combinação integrada de produtos e serviços que são capazes de atender a uma demanda específica do cliente (para entregar uma "unidade de satisfação"), com base em interações inovadoras entre os stakeholders do sistema de produção de valor (sistema de satisfação), onde o interesse econômico e competitivo dos provedores busca, continuamente, novas soluções ambientais e socioeticamente benéficas. Além disso, um PSS poderia proporcionar bem-estar social e prosperidade econômica, mesmo que isso possa ser complexo para projetar, testar e implementar.

De acordo com Vezzoli (2010), o design do sistema de produtos e serviços (PSS) articulado de forma eco-eficiente e socialmente justa e coesa, é capaz de satisfazer as necessidades e desejos específicos de um determinado grupo. O autor também diz que o Designer deve começar a aprender a desenvolver sistemas produto+serviço sustentáveis (SPSS) para encontrar soluções inovadoras que sejam capazes de integrar os interesses econômicos, ambientais e sociais. Para Briceno e Stagl (2006), a junção da dimensão social e econômica à dimensão ambiental mostrou limitações quanto à transformação do consumo e administração eficientes de projetos pelo PSS, que ocasionaram negligências nas questões sociais. As vantagens de adicionar o PSS às dinâmicas sociais estão inseridas principalmente no aumento do bem-estar da sociedade, já que o PSS oferece a possibilidade de envolvimento de todos os stakeholders no processo.

\section{Método e Desenvolvimento}

Dividiu-se a parte metodológica em quatro etapas: coleta de dados, aplicação de ferramentas de análise, aplicação de ferramentas de criação e prototipagem do serviço. A pesquisa tem natureza qualitativa e foi realizada por meio da aplicação de ferramentas de análise e criação do Design de Serviços, utilizando a pesquisa de campo com usuários da instituição de longa permanência e creche para idosos. Inicialmente realizou-se um Desktop Research (coleta de 
dados) para entender as problemáticas apontadas por pesquisas quantitativas, e logo após essa fase, houve a imersão no campo com visitas no lar e entrevistas narrativas com cuidadores, funcionários, familiares e principalmente com os idosos residentes na instituição. Todas as etapas da pesquisa foram desenvolvidas com a participação dos idosos e dicas de funcionários e familiares dos idosos da instituição.

\subsection{Coleta de Dados}

A etapa de coleta de dados foi desenvolvida a partir de revisão bibliográfica e benchmarking e aconteceu simultaneamente à aplicação das ferramentas de análise e criação. Na revisão bibliográfica encontrou-se uma série de informações relevantes sobre a mobilidade dos idosos e design de serviços, informações apresentadas na primeira seção deste artigo.

O benchmarking que, de acordo com Marsalia (2008), é um processo de medição e comparação que analisa e toma como exemplo, boas práticas de empresas líderes no setor estudado; foi utilizado nessa pesquisa para analisar empresas que realizam transporte de idosos. As empresas escolhidas para análise foram: Easy care saúde, DM remoção, Special Paraná e serviço de táxi. Dentre as empresas analisadas, a Easy care (figura 01) é voltada para atendimentos de saúde, realizando transporte de idosos em casos de emergência médica e também prestando serviço de atendimento médico em domicílio. Já a DM remoção é uma empresa que conta com uma variedade maior de serviços, realizando transporte de dependentes químicos, alcoólatras e também atendendo emergências médicas no geral. O Special Paraná é um serviço de transfer, que busca passageiros no aeroporto e leva até os hotéis. Os serviços de táxi também costumam ser utilizados por pessoas idosas no seu transporte diário.

Figura 1: Exemplo de Service Blueprint do Benchmarking realizado com a empresa Easy Care.

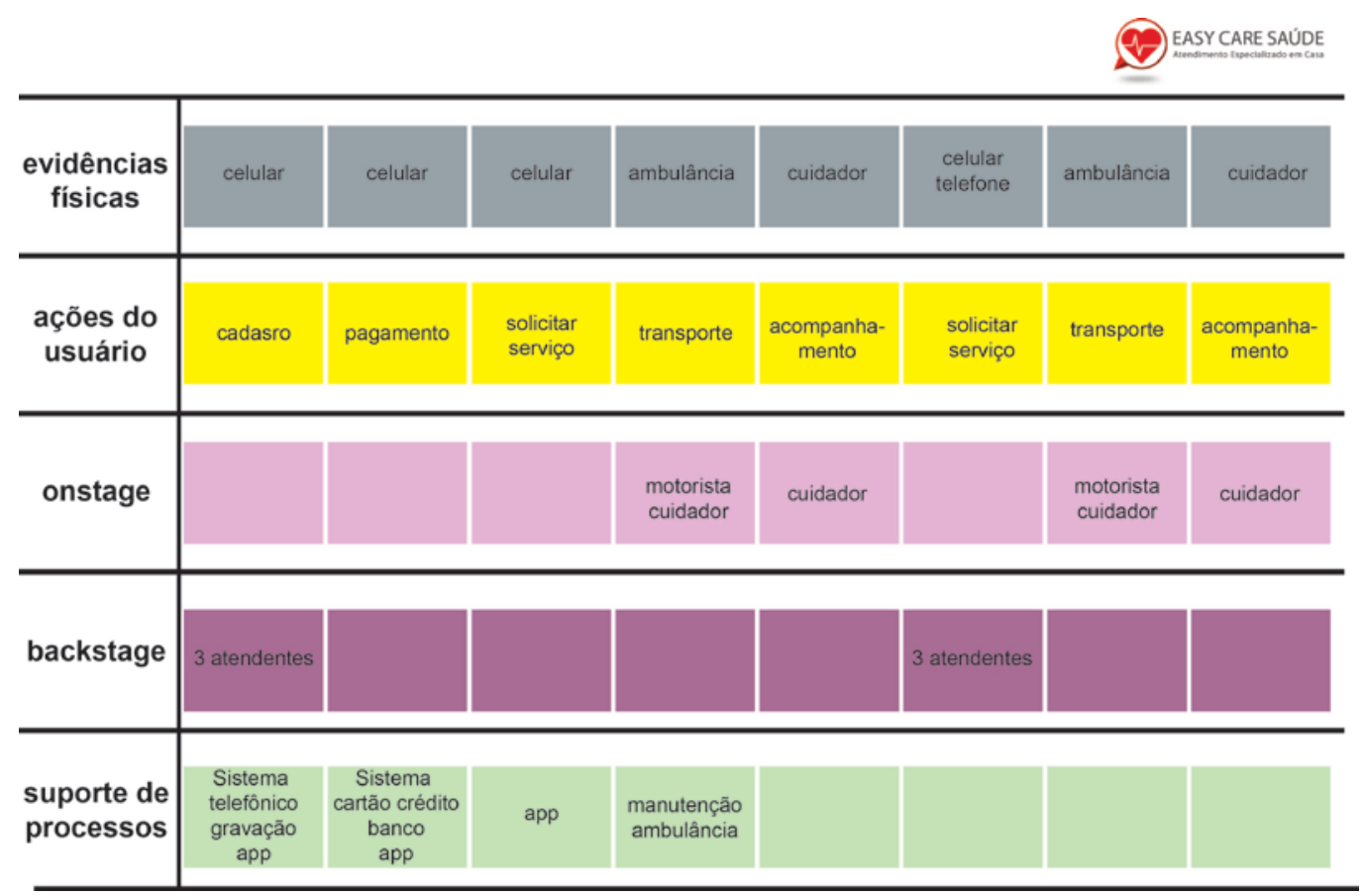

Fonte: Desenvolvido pelos autores. 
Nos dois primeiros serviços analisados verificou-se um foco em atendimentos médicos, sendo que ambos contam apenas com ambulâncias para realizar o transporte dos idosos. 0 serviço de transfer é comercializado com base na gentileza, cordialidade, destacando em seu website, que o motorista aguardará em caso de atrasos de voos e também fornece dicas sobre a cidade. Já o serviço de táxi foi interessante para o desenvolvimento do serviço, pois demonstrou, por meio dessa análise, que pessoas idosas costumam dar importância à amizade, procurando manter uma fidelidade ao seu taxista de confiança.

Buscou-se contato direto com o usuário desde as primeiras etapas da pesquisa para que fosse possível entender suas maiores dificuldades em assuntos relacionados à mobilidade e lhes dar voz no processo de criação do serviço. No design de sistemas produto + serviços o contato com o usuário acontece desde o início do processo de criação. De acordo com Muktar, Ismail e Yahya (2012) as empresas perceberam que ouvir o consumidor é importante para ser assertivo no mercado, pois com as novas tecnologias e possibilidades de feedback os consumidores passaram de passivos receptores a participantes ativos no desenvolvimento de produtos e serviços. Contataram-se algumas instituições de longa permanência para idosos em Curitiba-Pr, com o objetivo de investigar restrições a respeito da mobilidade dos idosos residentes. A escolha de instituições de longa permanência para a realização da pesquisa de deu por dois motivos: 1) facilidade em consultar e ter uma vivência com um maior número de idosos ao mesmo tempo; 2 ) maior dependência e consequentemente, dificuldade de transporte em relação aos idosos que vivem com suas famílias ou sozinhos.

A NurseAid foi uma empresa que chamou a atenção e se tornou relevante para a pesquisa, pois conta com um serviço diferenciado de creche para idosos. Um dos proprietários do lar relatou que esse serviço costuma ser mais utilizado para adaptação de idosos que se tornaram residentes do lar. O lar oferece aos idosos, terapia ocupacional, fisioterapia, musicoterapia, acompanhamento nutricional e serviços de enfermagem 24 horas. É uma instituição que conta com cuidados diários e uma boa estrutura física, porém a questão do transporte em casos de consultas médicas, lazer ou alguma outra necessidade do idoso depende exclusivamente da disponibilidade dos familiares. Foram realizadas entrevistas narrativas com 10 idosos residentes na instituição, com idades que variam entre 58 e 95 anos. Por meio de análises estatísticas estipularam-se perfis de idosos que poderiam utilizar o serviço de mobilidade e três foram selecionados para atuarem como personas reais para investigações mais profundas. Kainkainen et al. (2011), abordam a flexibilidade no desenvolvimento de serviços e o comparam a uma peça de teatro, nesse sentido chamam a atenção para a ferramenta de storytelling, pela qual o usuário é estimulado a contar uma história, que seria a base do roteiro da peça. Aplicou-se essa ferramenta com os idosos objetivando coletar dados sobre suas atuais condições de transporte e mobilidade. Assim, foram observadas algumas informações importantes que se repetiram nas histórias relatadas: i) sentimento de perda de autonomia; ii) falta de tempo das famílias para atividades de lazer, saúde e outras; iii) sentimento de solidão. A partir das informações coletadas partiu-se para a aplicação de ferramentas de análise desses dados, fornecida pelo Design de Serviços.

\subsection{Aplicação de Ferramentas de Análise}

Uma forma de aumentar a inclusão no Sistemas de Produto + Serviços é permitir a co-criação, ou seja, permitir que os usuários e clientes estejam conectados em todas as fases da 
pesquisa. Cloutier (2003) aponta a necessidade de haver a co-criação entre todos os stakeholders envolvidos quando se projeta para atender à uma necessidade social e inclusiva. Assim, as informações obtidas na storytelling foram analisadas por meio de duas ferramentas do design de serviços: matriz de pontos de contato e customer journey.

Blomkvist (2011) auxilia no entendimento dessas duas ferramentas quando afirma que as diferentes interações do serviço acontecem em conjunto com os usuários, pois é assim que o cliente consegue "tocar" o serviço, mesmo ele sendo intangível. Assim, a matriz de ponto de contato demonstrada na figura 02 , mostra todos os pontos nos quais o usuário interage com o serviço, demonstrando suas ações, o tempo e emoções.

Figura 2: Matriz de pontos de contato da persona 01.

\begin{tabular}{|c|c|c|c|c|c|c|c|c|c|c|}
\hline Horário & $10: 30$ & $10: 40$ & $10: 45$ & $10: 45$ & $11: 00$ & $11: 00$ & 11:05 & $11: 10$ & $11: 10$ & $14: 00$ \\
\hline $\begin{array}{l}\text { Pontos } \\
\text { de } \\
\text { Contato }\end{array}$ & $\begin{array}{c}\text { neto chega } \\
\text { no lar }\end{array}$ & $\begin{array}{l}\text { caminhar } \\
\text { portão }\end{array}$ & $\begin{array}{l}\text { entrar no } \\
\text { carro }\end{array}$ & conversar & estacionar & $\begin{array}{l}\text { sair do } \\
\text { carro }\end{array}$ & $\begin{array}{c}\text { subir } \\
8 \text { andar }\end{array}$ & $\begin{array}{c}\text { entrar no } \\
\text { apartamento }\end{array}$ & conversar & almoçar \\
\hline 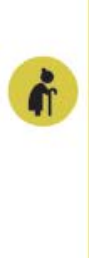 & (1). & $\begin{array}{c}\text { bengata } \\
\text { (2) } \\
\vdots \\
\vdots \\
\vdots \\
\text { cuidador }\end{array}$ & '? & $\begin{array}{l}{ }_{\operatorname{carro}} \\
\vdots \\
\vdots\end{array}$ & $\begin{array}{c}\text { carro (5) } \\
\therefore 1 \\
\therefore 1\end{array}$ & $6^{\prime}$ 'neto & olevador & $\underset{\text { neto }}{8}$ & $\begin{array}{l}\text { sots } \\
9 \\
1\end{array}$ & 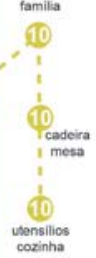 \\
\hline $\begin{array}{c}\text { Dores } \\
e \\
\text { Ganhos }\end{array}$ & ansiosa & ansiosa & alegria & alegria & apreensåo & apreensão & receito & timidez & $\begin{array}{l}\text { alegria } \\
\text { é } \\
\text { timidez }\end{array}$ & $\begin{array}{l}\text { alegria } \\
\text { timidez }\end{array}$ \\
\hline
\end{tabular}

Fonte: Desenvolvido pelos autores.

A matriz de pontos de contato foi desenvolvida de acordo com o trajeto do local onde a idosa mora até o apartamento da filha da persona 01, então foram relatados todos os pontos de contato com a ação, horários, as dores e os ganhos (emoções positivas e negativas) e os passos da jornada do usuário com os artefatos que foram sequencialmente numerados.

Após a criação da matriz de pontos de contato, esses dados foram usados em outra ferramenta de análise chamada Costumer Journey (TASSI, 2010), que é uma representação gráfica da jornada do usuário, ou seja, mapeia todos os pontos de contato do usuário em ordem de ocorrência por pontos, permitindo uma visualização do quadro geral do serviço e dos stakeholders envolvidos nessa interação. A figura 03 mostra a jornada do usuário em relação à mobilidade inicial dos idosos. 
Figura 3: Costumer Journey Map da persona 01.

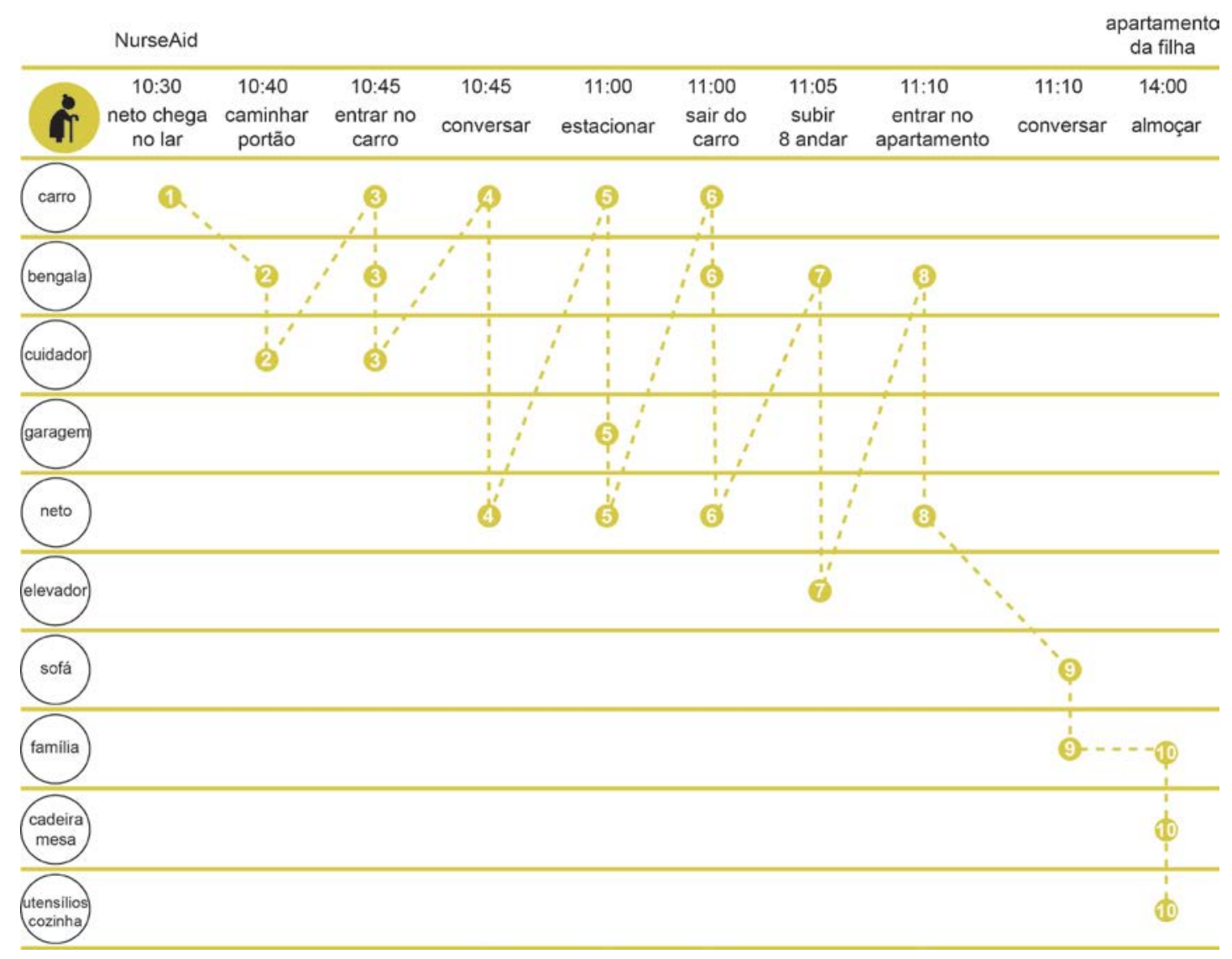

Fonte: Desenvolvido pelos autores.

As ferramentas de análise auxiliaram a entender a jornada de cada persona e apontar as lacunas existentes nas suas mobilidades. As informações obtidas na fase de coleta de dados foram comparadas aos discursos dos usuários e aos resultados da aplicação das ferramentas. Assim foi possível entender a necessidade de um serviço de locomoção para idosos que proporcionasse uma maior autonomia e tranquilidade aos usuários e segurança e controle a família.

\subsection{Aplicação de Ferramentas de Criação}

A partir dos resultados da aplicação das ferramentas de análise e interação direta com os idosos verificou-se problemas relacionados a redução da mobilidade. Na Tabela 01 constam os problemas encontrados e objetivos que visam a solução desses problemas, que forneceram informações para uma lista de Requisitos e Critérios para o novo serviço proposto. 
Tabela 1: Lista de Requisitos do Projeto.

\begin{tabular}{|c|c|c|c|}
\hline PROBLEMAS & OBJETIVOS & REQUISITOS & CRITÉRIOS \\
\hline Falta de autonomia & $\begin{array}{c}\text { Promover liberdade de ir e vir ao } \\
\text { idoso } \\
\text { Elevar autoestima }\end{array}$ & $\begin{array}{l}\text { Proporcionar } \\
\text { autonomia aos } \\
\text { idosos }\end{array}$ & Obrigatório \\
\hline \multirow[t]{2}{*}{$\begin{array}{l}\text { Falta de tempo dos } \\
\text { familiares para o } \\
\text { transporte dos } \\
\text { idosos }\end{array}$} & $\begin{array}{c}\text { Garantir transporte e } \\
\text { acompanhamento ao idoso sem a } \\
\text { presença física dos familiares }\end{array}$ & $\begin{array}{l}\text { Transporte } \\
\text { habilitado para } \\
\text { idosos sem os } \\
\text { familiares }\end{array}$ & Obrigatório \\
\hline & $\begin{array}{l}\text { Possibilitar aos familiares o } \\
\text { controle da locomoção do idoso } \\
\text { quando não estiverem presentes }\end{array}$ & $\begin{array}{l}\text { Controle do } \\
\text { transporte dos } \\
\text { idosos }\end{array}$ & Obrigatório \\
\hline $\begin{array}{l}\text { Vulnerabilidade } \\
\text { física e cognitiva }\end{array}$ & $\begin{array}{l}\text { Fornecer suporte ao idoso para } \\
\text { que realize atividades que envolva } \\
\text { mobilidade de forma segura }\end{array}$ & $\begin{array}{c}\text { Proporcionar } \\
\text { suporte, auxílio e } \\
\text { segurança aos } \\
\text { idosos }\end{array}$ & Obrigatório \\
\hline \multirow[t]{2}{*}{$\begin{array}{l}\text { Sentimento de } \\
\text { solidão }\end{array}$} & \multirow[t]{2}{*}{$\begin{array}{l}\text { Possibilitar a integração do idoso e } \\
\text { facilitar atividades de lazer, } \\
\text { entretenimento e cuidados em } \\
\text { ambientes externos }\end{array}$} & $\begin{array}{l}\text { Proporcionar } \\
\text { sentimento de } \\
\text { integração aos } \\
\quad \text { idosos }\end{array}$ & Desejável \\
\hline & & $\begin{array}{c}\text { Garantir acesso } \\
\text { seguro aos idosos }\end{array}$ & Desejável \\
\hline
\end{tabular}

Fonte: Desenvolvido pelos autores, 2018.

Por meio da identificação dos Requisitos partiu-se para a etapa de criação do novo modelo de PSS voltado a resolução dos problemas encontrados e atendimento aos critérios estabelecidos. Foi definido que a unidade de satisfação atendida seria relacionada a locomoção dos idosos, realizada de forma segura e empática, considerando particularidades de cada usuário e possibilitando às famílias um 'controle remoto' do processo de transporte. Considerando essas informações foram geradas 40 alternativas de serviços para idosos, que foram filtradas de acordo com unidade de satisfação a ser atendida e com a lista de requisitos de projeto, chegando-se ao serviço que mais atendeu as necessidades dos usuários. Dessa forma, foi realizado um bodystorming (figuras 04) junto aos usuários para tangibilizar o serviço. 
Figura 4:Representação gráfica do Bodystorming.
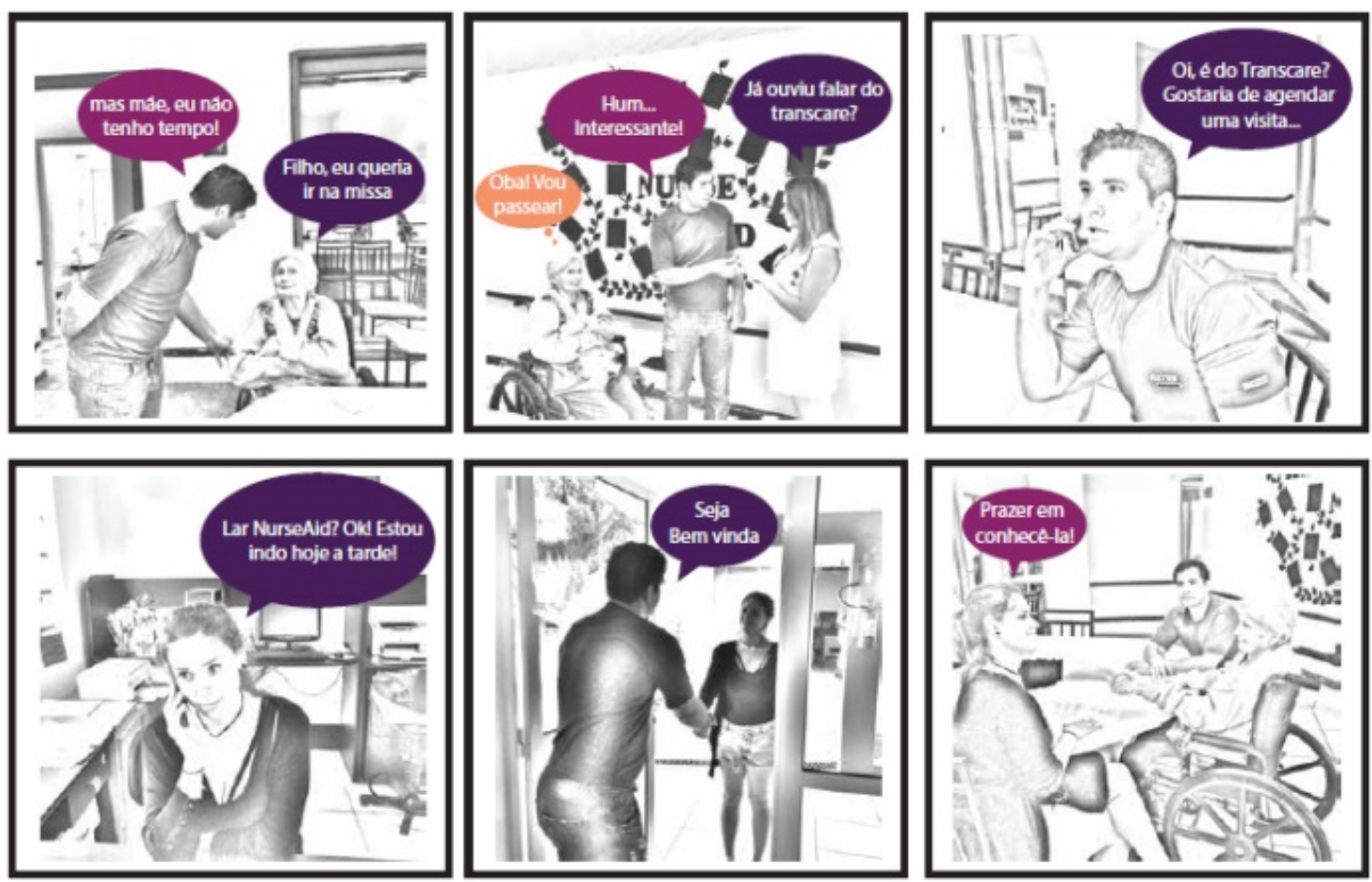

Fonte: Desenvolvido pelos autores,2018.

O bodystorming, segundo Blomkvist (2011), é uma técnica de criação e avaliação do serviço que está sendo desenvolvido que, dependendo do momento que é utilizada, ajuda a identificar os touchpoints (pontos de contato) e pode ser um teste para avaliar e considerar as melhores alternativas, assim como responder perguntas que serão identificadas na parte da prototipagem.

De acordo com a opinião de funcionários e moradores do lar que participaram da aplicação dessa ferramenta a melhor opção para o cadastro seria ter um consultor de vendas que fosse até o lar, ou mesmo até a residência de idosos que moram com suas famílias, para fazer o cadastro. Essa opção foi escolhida tanto por questão de tempo de deslocamento, quanto de praticidade, já que a locomoção de alguns idosos que usam cadeira de rodas, exige um carro habilitado e ajuda de mais de uma pessoa. Também foi consenso considerar a participação do idoso na tomada de decisões a respeito do serviço. A ideia é que o idoso e o familiar combinem lugares seguros onde o ele possa utilizar o serviço de forma autônoma, sendo que os responsáveis pelo fornecimento do serviço ficarão encarregados de manter o familiar informado quando idoso solicitar o transporte. Dessa forma o PSS desenvolvido trata-se de um PSS orientado a resultados (Tukker, 2003), pois os produtos envolvidos no sistema trabalham de forma autônoma para fornecer ao usuário um transporte seguro e empático. A partir da definição do PSS partiu-se para a etapa de prototipagem do serviço, na qual se procurou validar o funcionamento desse serviço. 


\subsection{Prototipagem do Serviço}

Assim como os novos produtos passam por um processo de prototipagem para serem validados, o mesmo acontece com os serviços. Para Blomkvist (2011) prototipar serviços é tão, ou até mais importante do que projetar produtos, pois uma série de valores intangíveis são verificados e avaliados nesse processo. $O$ autor destaca que nos serviços os pontos de contato a serem avaliados são muito maiores do que nos produtos, assim como as variáveis. A base dos serviços envolve relacionamentos humanos, de forma que não é possível prever todas as possíveis reações dos diferentes indivíduos envolvidos no fornecimento e recebimento do serviço. Para prototipar o serviço desenvolvido optou-se por duas técnicas: Tomorrow Readlines, Service Blueprint e um vídeo simulando a experiência.

O Tomorrow Readlines (figura 05) é uma técnica utilizada com o objetivo de prototipar, com baixa fidelidade, o serviço para que o usuário visualize de forma mais clara sobre o serviço.

Figura 05: Tomorrow Readlines.

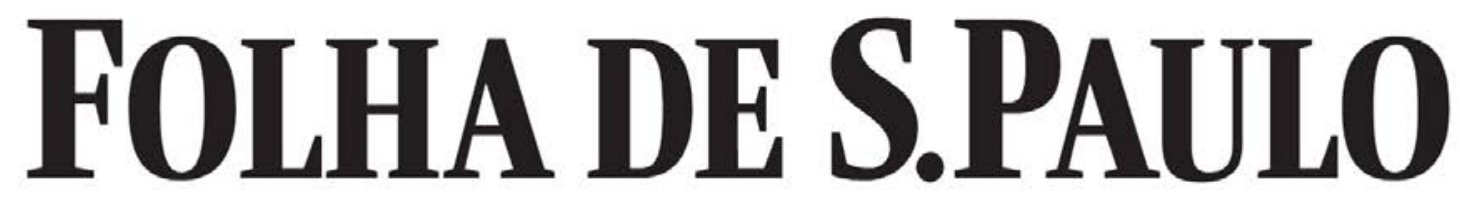

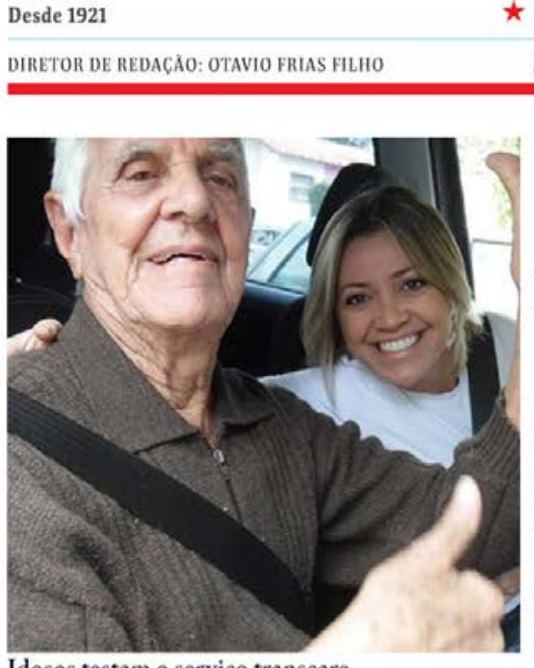

Idosos testam o serviço transcare $\star \star \star$ UM JORNAL A SERVICO DO BRASIL

ANO $94 *$ QUARTA-FEIRA, 9 DE ABRIL DE $2014 *$ N031.052

\section{Transcare serviço de transporte para idosos modificando conceitos}

Agora os idosos podem ir ao médico, passeios ou outras atividades com segurança e acompanhamento da familia por aplicativos de celular com o serviço Transcare

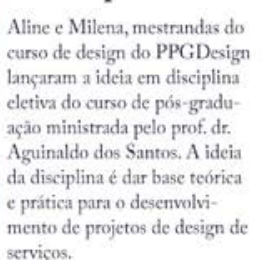
serviços.
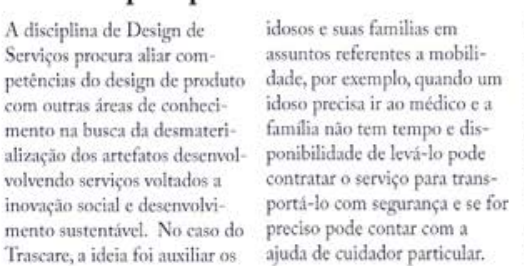

Fonte: Desenvolvido pelos autores, 2018.

O Service Blueprint foi utilizado para detalhar e visualizar as etapas e pontos de contato do serviço desenvolvido. Para Geum e Park (2011) a maior dificuldade em um processo de detalhar e simular etapas de uma experiência é envolver tanto os produtos, quanto os serviços que fazem parte e elucidam essa jornada. Para os autores esta é uma ferramenta que atua como um mapa que retrata o Sistema Produto+Serviço evidenciando todos os componentes desse sistema e possibilitando uma visão geral desse sistema.

No Service Blueprint desenvolvido constam todas as ações do usuário em cada etapa do 
processo do serviço, relacionados com as evidências físicas utilizadas no processo. Sendo que onstage e backstage são relacionados com os pontos de contato diretos, frente a frente com o usuário e indiretos, que estão acontecendo por trás da cena para possibilitar a execução do serviço. O suporte de processos é relacionado com os fatores que envolvem suporte de sistema e redes que apoiam as etapas do serviço.

O vídeo foi desenvolvido pela própria equipe de pesquisadores no laboratório de fotografia da Universidade Federal do Paraná com o auxílio de câmera, objetos para simular o serviço e colegas para representar os envolvidos. Foram produzidas três cenas, sendo que a primeira simula a solicitação do serviço, na qual a idosa solicita o serviço, recebe confirmação no dia marcado, aguarda e recebe o motorista. Na segunda cena o motorista entra na garagem do lar para buscar a idosa, a ajuda a entrar no carro, conversa cordialmente, coloca uma playlist selecionada pela idosa e sua família e o transporte acontece tranquilamente. E por fim, na terceira cena é simulada uma situação onde a idosa passa mal durante o serviço e é prontamente atendida pelo motorista que tem conhecimento em primeiros socorros, este avisa a família e leva a idosa até um pronto atendimento médico.

Dessa forma foi possível visualizar o serviço e simular algumas situações possíveis, porém é impossível determinar as variáveis que podem ocorrer na aplicação real de um serviço como este. Desta forma optou-se por simular situações importantes para o serviço, como a forma de tratamento por exemplo, com o objetivo de perceber detalhes que podem ser melhorados, mas levando em consideração que esses detalhes continuarão surgindo mesmo no cotidiano de um serviço já implantado.

\section{Resultados e Discussões}

Com esta pesquisa foi possível observar uma nova forma para contribuir com o desenvolvimento de soluções em design: o sistema de produto + serviços. Com a criação de um sistema integrado de produtos e serviços (PSS) observa-se que é possível solucionar problemas cotidianos pensando em qualidades intangíveis, com o objetivo de diminuir a materialidade presente nos produtos físicos. Dessa forma o PSS pode ser um caminho para a sustentabilidade (VEZZOLI, 2010; BLOMKVIST, 2011).

No caso do PSS desenvolvido é oferecido aos clientes e usuários uma solução em transporte, habilitada para o público idoso. O aluguel dos veículos utilizados seria um fator positivo tanto de forma sustentável quanto econômica, pois não seria necessária a aquisição de novos bens de consumo. Outro ponto a ser considerado neste sentido são os idosos que vivem sozinhos, optando pelo serviço não precisariam ser proprietários de automóveis, pois, quando necessário, contariam com os serviços habilitados e seguros da empresa. Esses fatores indicam uma diminuição da demanda por novos veículos no mercado, contribuindo com a desmaterialização do consumo e consequente com o consumo sustentável.

Em relação ao sentimento dos idosos de perda de autonomia identificado como um dos problemas-chave dessa pesquisa entende-se que a possibilidade de solicitar o serviço, sem dependência de horários dos familiares, ajuda a amenizar a perda. De acordo com a conversa com os residentes do lar, muitos idosos deixam de sair ou realizar atividades que gostam por não 
querer tomar o tempo dos familiares, que na maioria das vezes trabalham em horário integral. Com o serviço de transporte os idosos ficam livres deste sentimento, pois a empresa funciona exclusivamente para atender a necessidade de transporte desses usuários. Com a possibilidade de transporte $\mathrm{o}$ ancião pode se integrar socialmente, adquirindo liberdade para visitar amigos, atividades religiosas, fazer algumas comprar, ir a consultas e outras atividades desde que previamente combinadas com o serviço de transporte e sua família.

O serviço também auxilia a família do usuário, possibilitando tranquilidade e segurança por meio de um controle remoto por aplicativo das solicitações e trajetos do idoso, possuindo autonomia para interferir em qualquer etapa do processo de transporte, pois conta com comunicação direta com o suporte do serviço.

Acredita-se que os resultados do serviço desenvolvido são muito positivos para melhorar a qualidade de vida dos idosos e de suas famílias, principalmente em um contexto no qual essa população vem crescendo cada vez mais (IBGE, 2012). A imersão no contexto dos usuários auxiliou desde a identificação do problema, até a etapa de avaliação e prototipagem, pois permitiu que os usuários participassem e interferissem no desenvolvimento do serviço que é voltado à eles próprios. Assim, foi possível desenvolver um serviço eficiente mas que ainda é necessário testar e prototipar outras possíveis situações, para aplicação do serviço no mundo real. Dessa forma estuda-se a possibilidade de parcerias com empresas para viabilizar a implantação do novo serviço desenvolvido.

\section{Referências}

BLOMKVIST, J. Conceptualising Prototypes in Service Design. 2011. 149 f. Tese (Doutorado em Computação e Ciências da Informação) Faculty of Arts and Sciences, Linköping University, Suécia, 2011.

BRICENO, T.; STAGL, S. The role of social processes for sustainable consumption. Journal of Cleaner Production. Vol14. p 1541-1551. 2006.

CAMARANO et al. Características das Instituições de Longa Permanência para Idosos da Região Sul. IPEA. Brasília, Presidência da República, 2008.

Censo 2012. IBGE, Rio de Janeiro, 2012. Disponível em: www.ibge.gov.br/home/estatistica/populacao/estimativa2012. Acesso em abril 2017.

CESCHIN, F.; GAZIULUSOY.I. Evolution of design for sustainability: From product design to design for system innovations and transitions. Design Studies. vol47. p118-163. 2016.

CLOUTIER, J. Qu'est-ce que l'innovation sociale? Cahier du CRISES, Collection Études théoriques, no ET0314 SBN : 2-89605-135-X Dépôt légal: Québec, 2003.

COSTA JUNIOR, J. Proposição de um Modelo de Referência para o Design de Serviços Ecoeficientes em Sistemas Produto-Serviço. 2012. 201 f. Dissertação (Mestrado em Design) Universidade Federal do Paraná, Curtiba, 2012.

GEUM, Y.; PARK, Y. Designing the sustainable product-service integration: a product-service blueprint approach. In: Journal of Cleaner Production. Elsevier, 2011. p. 1601 - 1614. 
GOEDKOOP, M.; VAN HALEN, C.; RIELE, H.; ROMMENS, P. Product service system: ecological and economic basics. Technical Report. Storrm, C.C., 1999.

HOSS, M. J. Prototipagem de serviços: um estudo exploratório com foco na iluminação de habitações de interesse social. 2014. 182 f. Dissertação (Mestrado em Design) Universidade Federal do Paraná, Curtiba, 2012.

KANKAINEN, A; VAAJAKALLIO, K; KANTOLA, V; MATTELMAKI, T. Storytelling Group - a co-design method for service design. In: Behaviour \& Information Technology. Taylor e Francis, Reino Unido, 2011. p. $221-230$.

MARSALIA, L; MACEDO, M. O.; RODRIGUES, R. S.; CARVALHO, W.; DUTRA, K. E. Benchmarking: um instrumento para o mundo moderno. In: Revista Eletrônica da Faculdade Metodista Granbery. Curso de Educação Física, 2008.

Mukhtar, M., Ismail, M. N., \& Yahya, Y. (2012). A hierarchical classification of co-creation models and techniques to aid in product or service design. Computers in Industry, 63(4), 289-297.2012.

Organização Mundial da saúde (OMS). Disponível em: www.who.int/about/es/. Acesso em abril de 2017.

ROSA, et al. Perfil epidemiológico de idosos que foram a óbito por queda no Rio Grande do Sul. Revista Brasileira de Geriatria e Gerontologia, v. 18, n. 1, p. 59-69, 2015.

TUKKER, A. Eight types of product-service systems: eight ways to sustainability? Conference paper. 11th International Conference of Greening of Industry Network / Innovating for Sustainability. San Francisco, 2003.

Vezzoli et al. Newdesign challenges to widely implement 'Sustainable Product-Service Systems'. Journal of Cleaner Production. Vol 97. 2015.

VEZZOLI, C. Design de Sistemas para a Sustentabilidade: teoria, métodos e ferramentas para o design sustentável de "sistemas de satisfação". 343P. EDUFBA. Salvador. 2010. 